\title{
Crystallization-Driven Self-Assembly of Metallo-Polyelectrolyte Block Copolymers with a Polycaprolactone Core-Forming Segment
}

Yujin Cha, ${ }^{\dagger}$ Charles Jarrett-Wilkins, ${ }^{\ddagger}$ Md Anisur Rahman, ${ }^{\dagger}$ Tianyu Zhu, ${ }^{\dagger}$ Ye Sha, ${ }^{\dagger}$ Ian Manners,, ${ }^{\dagger+*}$ and Chuanbing Tang ${ }^{\dagger *}$

${ }^{\dagger}$ Department of Chemistry and Biochemistry, University of South Carolina, Columbia, South Carolina, 29208, United States

‡School of Chemistry, University of Bristol, Cantock’s Close, Bristol BS8 1TS, United Kingdom

${ }^{\dagger+}$ Department of Chemistry, University of Victoria, 3800 Finnerty Road, Victoria BC, V8P 5C2, Canada

\section{Supporting Information}

\section{Experimental}

Materials. Cobaltocenium amidoethyl methacrylate hexafluorophosphate was synthesized according to a previously reported procedure. ${ }^{1} \varepsilon$-Caprolactone (98\%) was purchase from Sigma Aldrich and distilled with calcium anhydride. Benzyl alcohol (98\%, Sigma Aldrich) was distilled before use. Azobisiobutyronitrile (AIBN) was purchase from Sigma Aldrich and recrystallized in methanol. Copper iodide, propargyl alcohol, stannous octoate tetrabutylammonium chloride, 4cyano-4-(phenylcarbonothioylthio)pentanoic acid and 4-( N,N-dimethylamino)pyridine were purchased from Sigma Aldrich and used as received without further purification.

Characterization. ${ }^{1} \mathrm{H}$ NMR spectra were recorded by a Bruker Avance III HD 300 using trimethylsilane an internal standard. Molecular weight and molecular weight distribution of polymers were determined by gel permeation chromatography (GPC) with tetrahydrofuran (THF) as an eluent at a flow rate of $1 \mathrm{~mL} / \mathrm{min}$ at $35^{\circ} \mathrm{C}$ on a Waters GPC system equipped with a refractive index (RI) detector, and narrow dispersed polystyrene was used for calibration. Atomic force microscopy (AFM) was performed using a Multimode Nanoscope V system (Bruker, Santa 
Barbara, CA). Tapping mode AFM was used to map the topography by tapping the surface using an oscillating tip. Transmission Electron Microscopy (TEM) images were collected from JEOL 200CX transmission electron microscope with an acceleration voltage of $120 \mathrm{kV}$. The samples were prepared by drop casting onto a copper grid and dried before measurement.

\section{Polymer Synthesis}

Scheme S1. Synthesis of polycaprolactone.
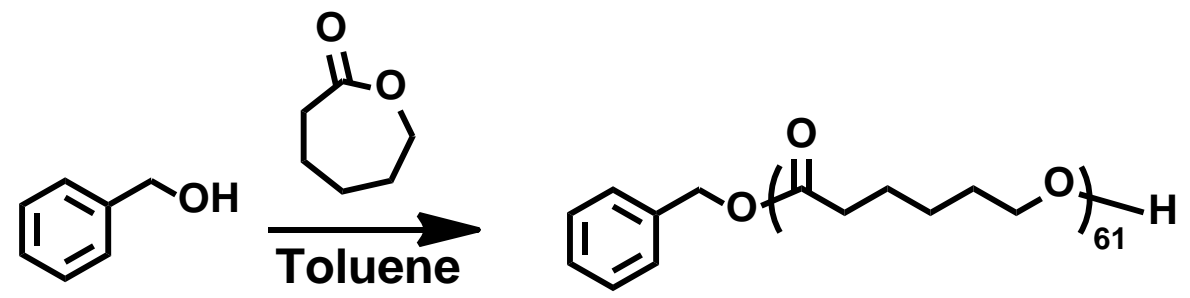

Synthesis of polycaprolactone homopolymer with -OH end group. PCL was prepared by ringopening polymerization of $\varepsilon$-caprolactone. The procedure was performed according to previous work. $^{2}$ Stannous octoate was used as a catalyst and benzyl alcohol was used as an initiator. $\varepsilon$ Caprolactone (3.0 g, $26.3 \mathrm{mmol}$ ), benzyl alcohol (90 mg, $0.12 \mathrm{mmol}$ ), and stannous octoate (50 mg, 0.12mmol) were placed in a $25 \mathrm{~mL}$ flame-dried round bottom flask. The mixture was dissolved in $5.0 \mathrm{~mL}$ toluene. The reaction solution was purged with nitrogen for 30 minutes, and placed into an oil bath preheated to $110{ }^{\circ} \mathrm{C}$. The polymerization was proceeded for 3 hours and quenched by cooling the reaction mixture in an ice-water bath. The polymer was precipitated into cold methanol 3 times (2.41g, ca. 80\% yield). The repeating unit of polymer was calculated to be 61 by ${ }^{1} \mathrm{H}$ NMR analysis. $M_{n}(\mathrm{GPC})=6,500 \mathrm{~g} / \mathrm{mol}, Ð=1.25 .{ }^{1} \mathrm{H} \mathrm{NMR}\left(\mathrm{CDCl}_{3}, \mathrm{ppm}, 300 \mathrm{MHz}\right): \delta=7.36(\mathrm{br}, 5 \mathrm{H}$, PhCH $\mathrm{O}_{2} \mathrm{O}-$ ), 5.13 (s, 2H, $\mathrm{PhCH}_{2} \mathrm{O}-$ ), 4.07 (t, 120H, $-\mathrm{COOCH}_{2} \mathrm{CH}_{2}$ ), 3.66 (t, 2H, $\left.\mathrm{CH}_{2} \mathrm{CH}_{2} \mathrm{OH}\right), 2.32(\mathrm{t}$, 
$120 \mathrm{H},-\mathrm{OCOCH} \mathrm{CH}_{2}-$ ), 1.68-1.61 (m, $240 \mathrm{H}$, $-\mathrm{COOCH}_{2} \mathrm{CH}_{2} \mathrm{CH}_{2} \mathrm{CH}_{2} \mathrm{CH}_{2} \mathrm{OH}$ ), 1.43-1.36 (m, $140 \mathrm{H}$, $\left.-\mathrm{COOCH}_{2} \mathrm{CH}_{2} \mathrm{CH}_{2} \mathrm{CH}_{2} \mathrm{CH}_{2} \mathrm{OH}\right)$.

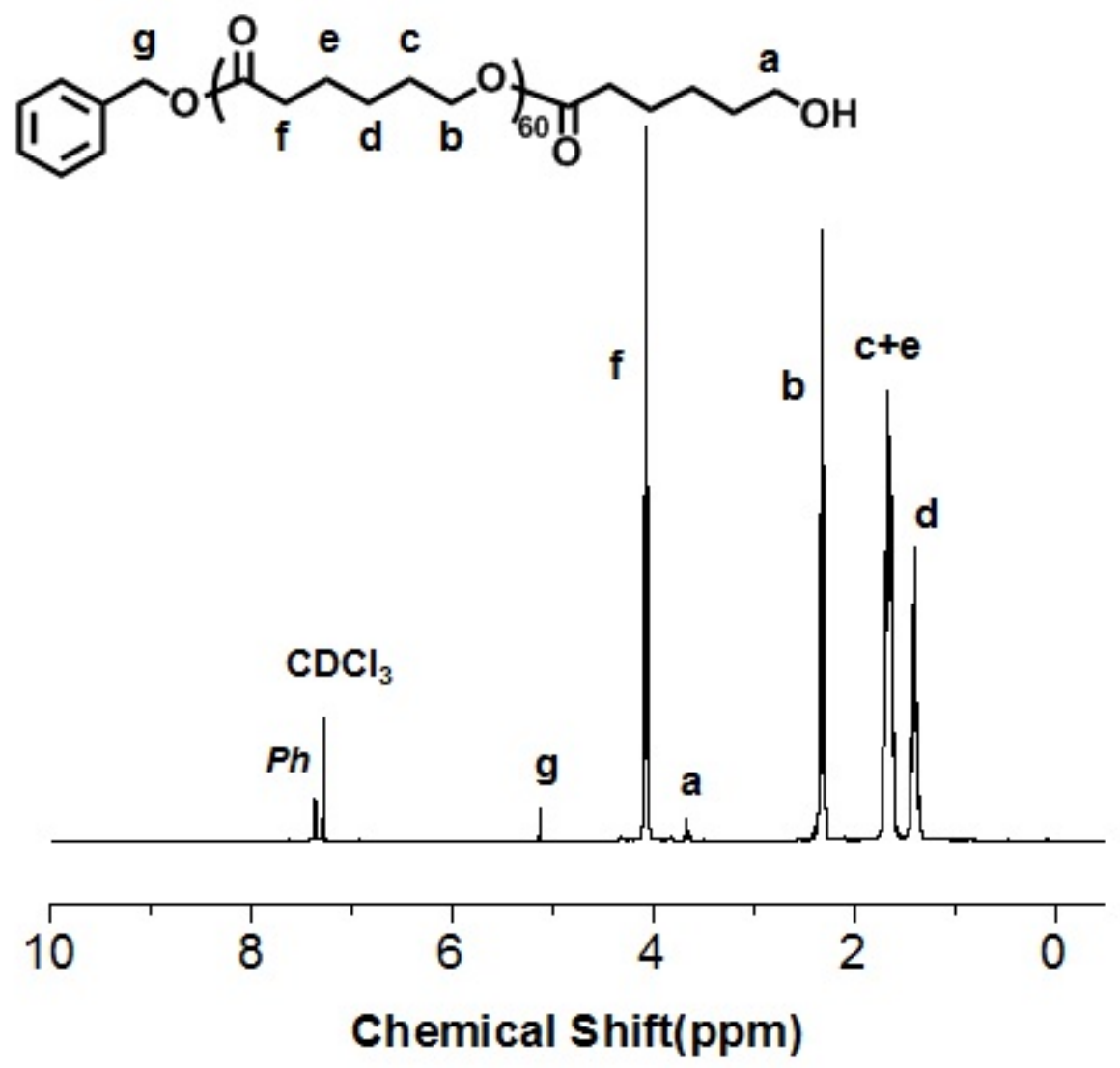

Figure S1. ${ }^{1} \mathrm{H}$ NMR spectrum of $\mathrm{PCL}_{61}-\mathrm{OH}$. 
Scheme S2. Synthesis of PCL with terminal azide.
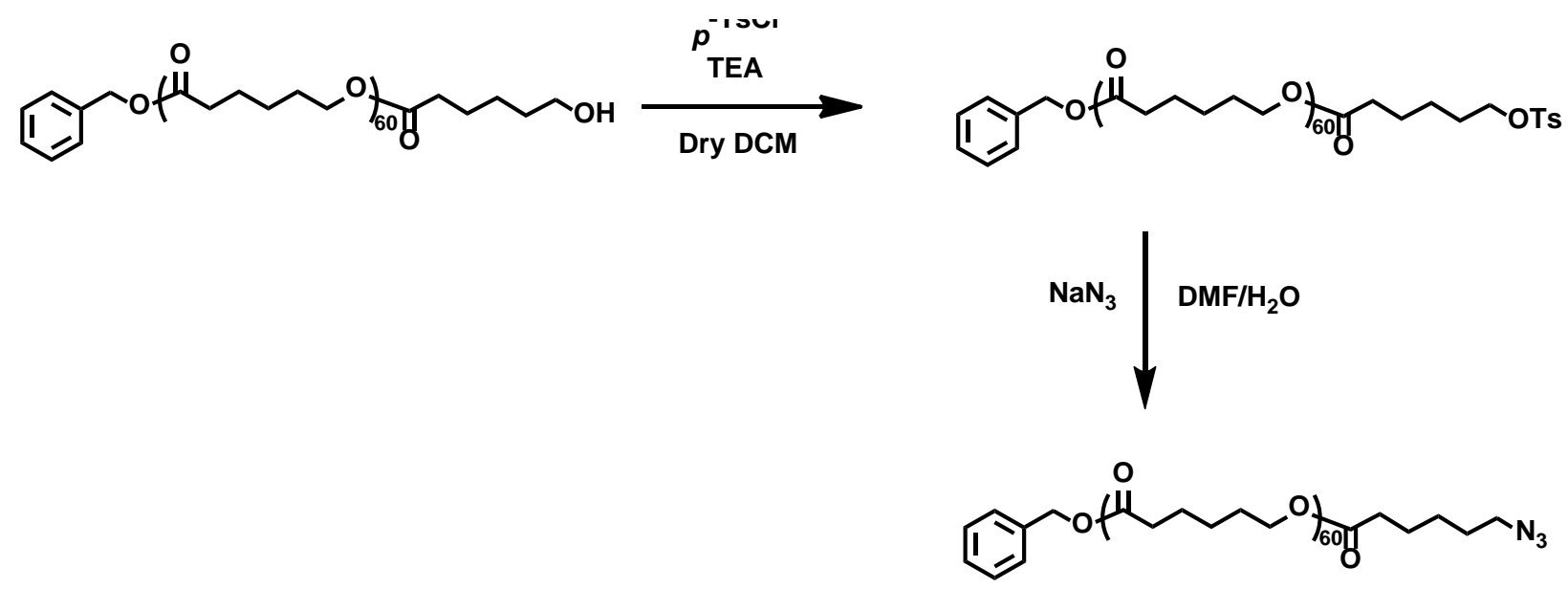

Modification of PCL-OH with azide. The hydroxyl end group of PCL-OH was converted to azide via two step modifications: tosylation and azide substitution. PCL-OH homopolymer (1.5 g, $0.25 \mathrm{mmol}$ ) was dissolved in $5 \mathrm{~mL}$ dicholoromethane (DCM) and added by trimethylamine (0.35 $\mathrm{ml}, 2.54 \mathrm{mmol}$ ). The reaction solution was cooled in an ice bath. $p$-Toluenesulfonyl chloride (484 mg, $2.54 \mathrm{mmol}$ ) was dissolved in $5 \mathrm{~mL}$ DCM and added to the above reaction mixture dropwise. After 24 hours, the tosylated polymer was precipitated in cold methanol three times. PCL-OTs was converted to PCL-N $\mathrm{N}_{3}$ by reaction with sodium azide in dimethylformamide (DMF). PCL-OTs (1.04 g, $0.14 \mathrm{mmol}$ ) and sodium azide (650 mg, $10 \mathrm{mmol}$ ) were dissolved in dry DMF. The reaction was proceeded at room temperature for 24 hours. The reaction mixture was extracted using DCM and brine three times to remove excess sodium azide. The organic layer was dried with anhydrous $\mathrm{MgSO}_{4}$. The PCL-N3 product was recovered by precipitation in cold methanol (1.1 g, 73\% yield). Azide substitution was confirmed by IR spectrum (Figure S3). ${ }^{1} \mathrm{H}$ NMR (CDCl 3 , 300MHz, ppm): $\delta=7.30$ (br, 5H, $\mathrm{PhCH}_{2} \mathrm{O}-$ ), 5.05 (s, 2H, $\mathrm{PhCH}_{2} \mathrm{O}-$ ), 3.99 (t, 120H, $-\mathrm{COOCH}_{2} \mathrm{CH}_{2}$ ), 3.26 (t, 2H, $\mathrm{CH}_{2} \mathrm{CH}_{2} \mathrm{~N}_{3}$ ), 2.32 (t, $120 \mathrm{H},-\mathrm{OCOCH}_{2} \mathrm{CH}_{2}-$ ), 1.63-1.53 (m, $240 \mathrm{H},-\mathrm{COOCH}_{2} \mathrm{CH}_{2} \mathrm{CH}_{2} \mathrm{CH}_{2} \mathrm{CH}_{2} \mathrm{~N}_{3}$ ), 1.36-1.29 (m, $140 \mathrm{H},-\mathrm{COOCH}_{2} \mathrm{CH}_{2} \mathrm{CH}_{2} \mathrm{CH}_{2} \mathrm{CH}_{2} \mathrm{~N}_{3}$ ). 


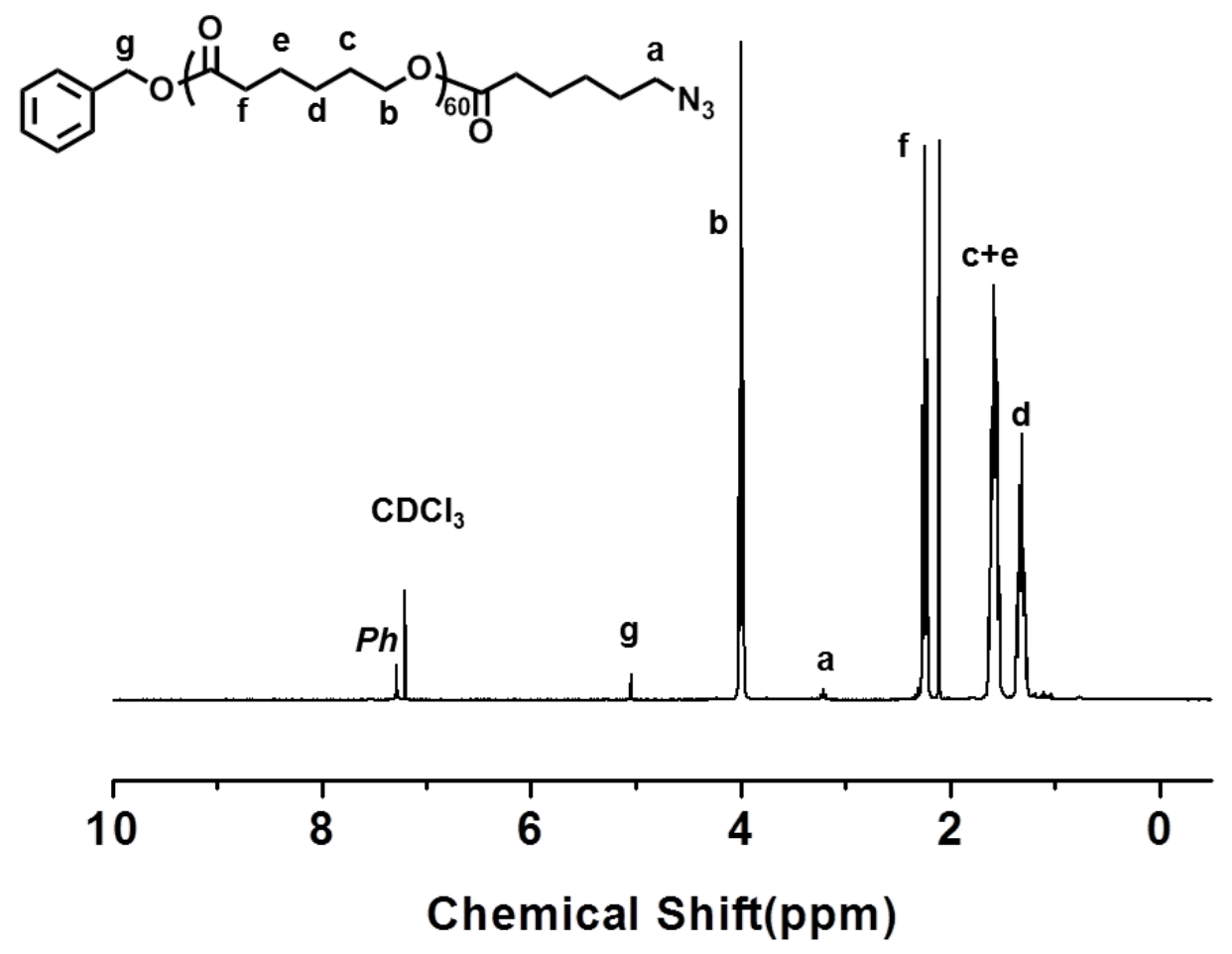

Figure S2. ${ }^{1} \mathrm{H}$ NMR spectrum of PCL-N 3 . 


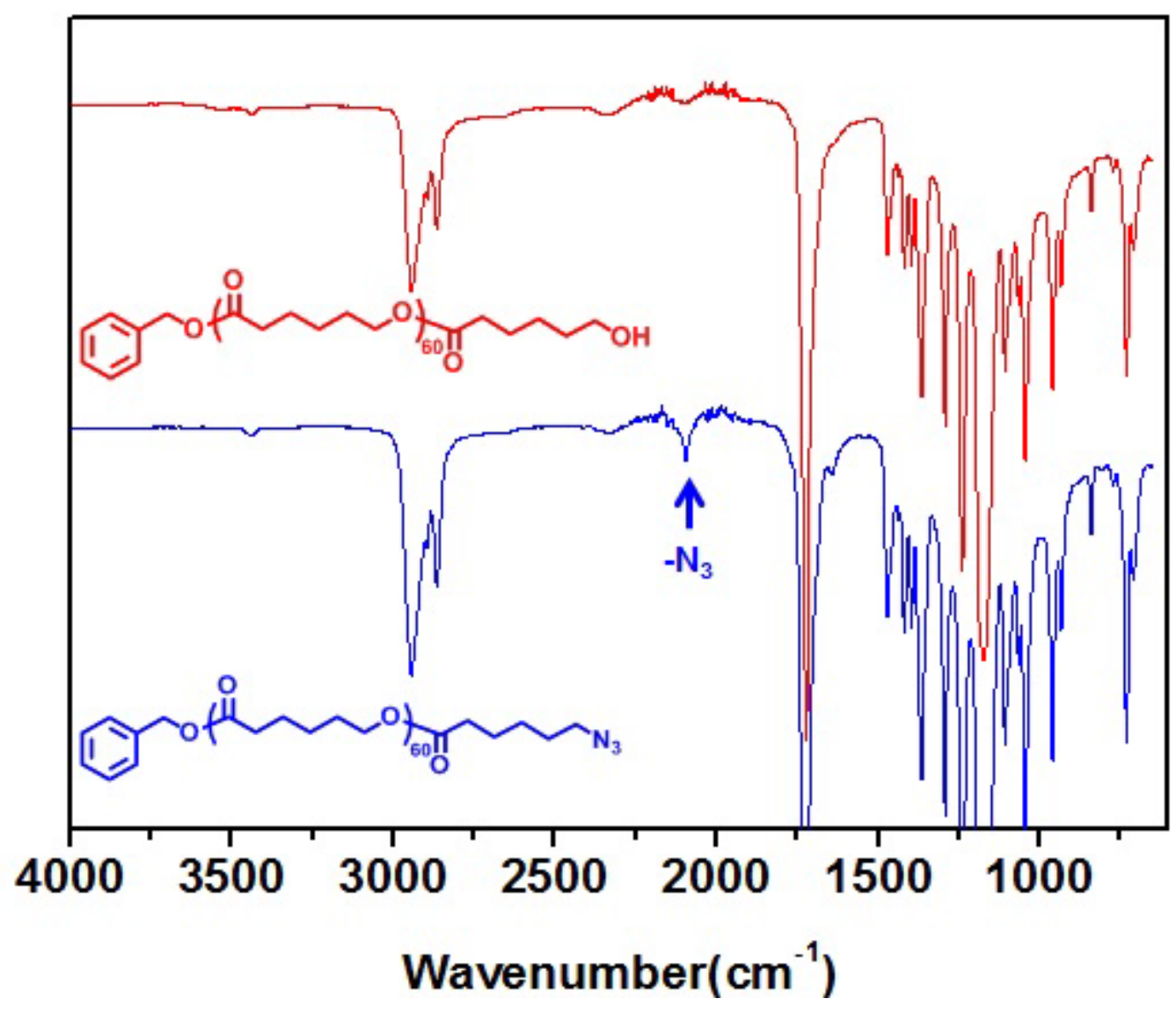

Figure S3. IR spectra of PCL-OH and PCL-N3.

Scheme S3. Synthesis of terminal alkyne modified CTA.<smiles>C#CCOC(=O)CC(C)(C)SC(=S)c1ccccc1</smiles>

Synthesis of alkyne modified CTA. RAFT agent, 4-cyano-4-(phenylcarbono thioylthio) pentanoic acid (CPPA), was modified with propargyl alcohol via esterification. CPPA (0.5 g, 1.79 mmol), 4-dimethylaminopyridine (DMAP) (22 mg, $0.18 \mathrm{mmol})$ and propargyl alcohol (0.5 g, 0.89mmol) were placed into a round bottom flask, then added with $20 \mathrm{~mL}$ dry DCM and placed in 
an ice bath. 1-Ethyl-3-(3-dimethylaminopropyl)carbodiimide (EDC) (0.3 g, $1.93 \mathrm{mmol})$ was dissolved in dry DCM and added into the above reaction mixture dropwise. After addition of EDC, TEA ( $0.5 \mathrm{ml}, 0.36 \mathrm{mmol})$ was added immediately. The reaction mixture was stirred for 24 hours. The reaction mixture was extracted by water for three times. The organic layer was dried with anhydrous $\mathrm{MgSO}_{4}$ and condensed by rotary evaporation. The product was purified by silica column chromatography using hexane and ethyl acetate (1:1) as eluent. The product was collected and dried under vacuum. ${ }^{1} \mathrm{H}$ NMR $\left(\mathrm{CDCl}_{3}, 300 \mathrm{MHz}, \mathrm{ppm}\right): \delta=7.93(\mathrm{~d}, 2 \mathrm{H}, P h-), 7.48(\mathrm{t}, 1 \mathrm{H}$, $P h-), 7.33$ (t, 2H, Ph-), 4.66(s, 2H, -OCH $\mathrm{OCCH}_{2}$ ), 2.75-2.36(m, 5H, - $\mathrm{CH}_{2} \mathrm{CH}_{2}-$, -CCH), 1.87(s, 3H, $\left.-\mathrm{CH}_{3}\right)$.
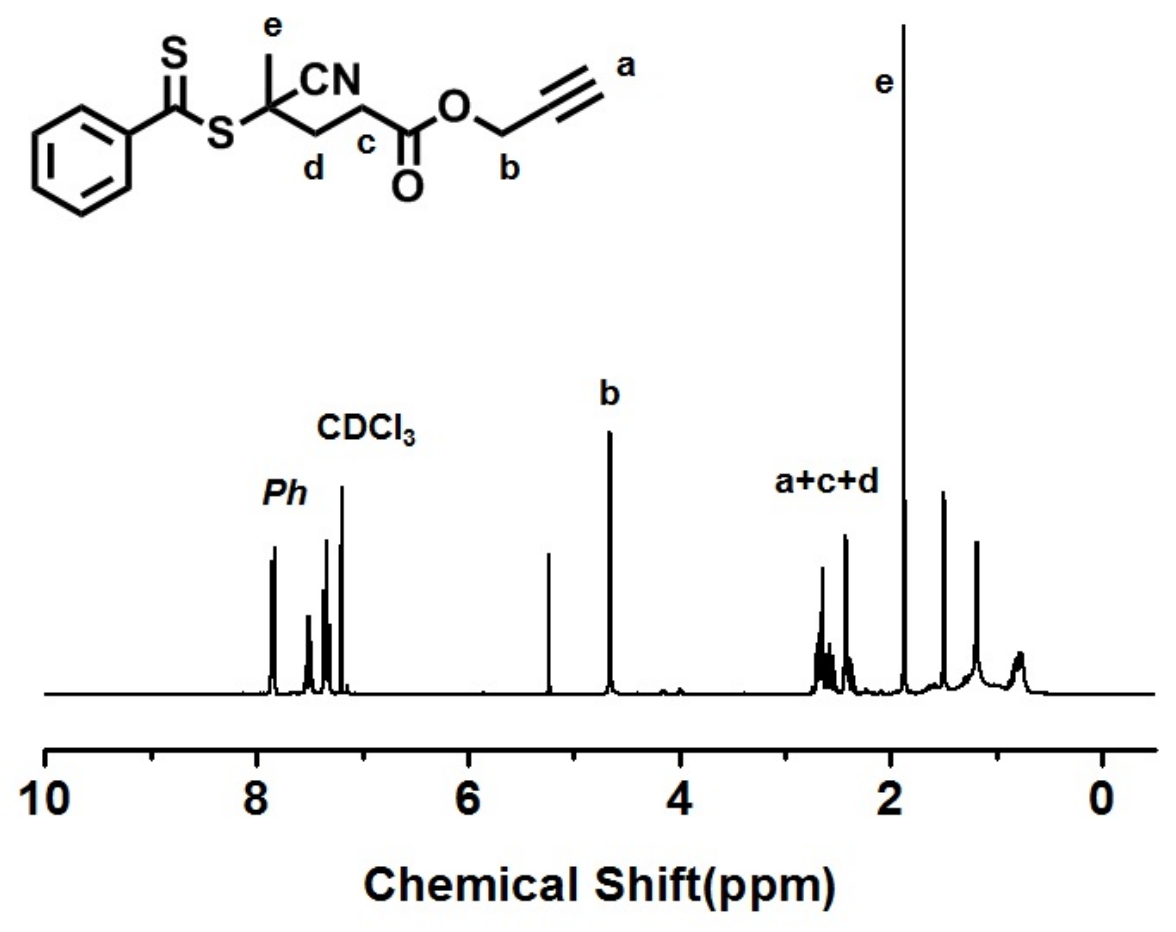

Figure S4. ${ }^{1} \mathrm{H}$ NMR spectrum of alkyne-modified CTA. 
Scheme S4. Synthesis of PCL macro-initiator.
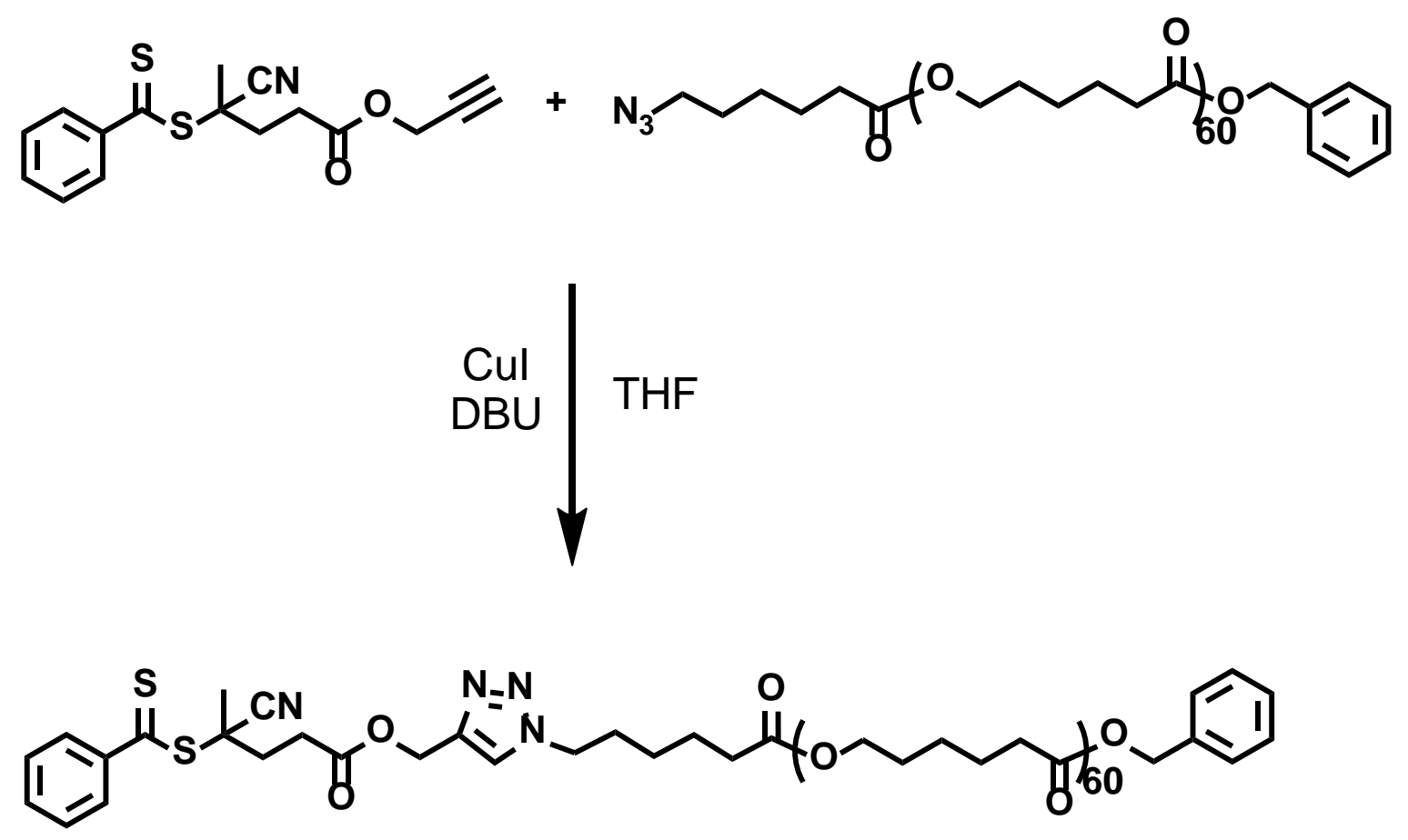

Synthesis of PCL Macro-CTA. Synthesis of PCL-RAFT agent was obtained by click reaction between PCL-N3 and alkyne modified CPPA. Copper(I) iodide $(0.8 \mathrm{mg}, 4.2 \mu \mathrm{mol})$ and 1,8diazabicyclo[5.4.0]undec-7-ene (DBU) $(0.96 \mathrm{mg}, 6.3 \mu \mathrm{mol})$ were dissolved in $3 \mathrm{ml}$ dry tetrahydrofuran (THF). PCL-N 3 (0.3 g, 0.042 mmol) and alkyne modified CPPA (107 mg, 0.34 mmol) were dissolved in $10 \mathrm{~mL}$ dry THF ands purged with nitrogen. A mixture of DBU and CuI was added to the above reaction mixture. The mixture was stirred for 24 hours and diluted with 10 $\mathrm{ml}$ DCM. The mixture was extracted with water to remove residual reagents. The product was recovered by precipitation in cold methanol and dried under vacuum. ${ }^{1} \mathrm{H} \mathrm{NMR}\left(\mathrm{CDCl}_{3}, 300 \mathrm{MHz}\right.$, ppm): $\delta=7.81$ (d, 2H, Ph-), 7.51 (m, 3H, Ph-, Triazole), 7.28 (m, 6H, Ph-), 5.19 (s, 2H, $\mathrm{CH}_{2}$ Triazole-), 5.05 (s, $\left.2 \mathrm{H}, \mathrm{PhCH}_{2} \mathrm{O}-\right), 4.01$ (t, 120H, $\left.-\mathrm{COOCH}_{2} \mathrm{CH}_{2}\right), 2.25$ (t, 120H, $\left.\mathrm{OCOCH}_{2} \mathrm{CH}_{2}-\right)$, 1.62-1.53 (m, 240H, - $\mathrm{COOCH}_{2} \mathrm{CH}_{2} \mathrm{CH}_{2} \mathrm{CH}_{2} \mathrm{CH}_{2}$ ), 1.36-1.29 (m, 120H, $\mathrm{COOCH}_{2} \mathrm{CH}_{2} \mathrm{CH}_{2} \mathrm{CH}_{2} \mathrm{CH}_{2}$ ). 


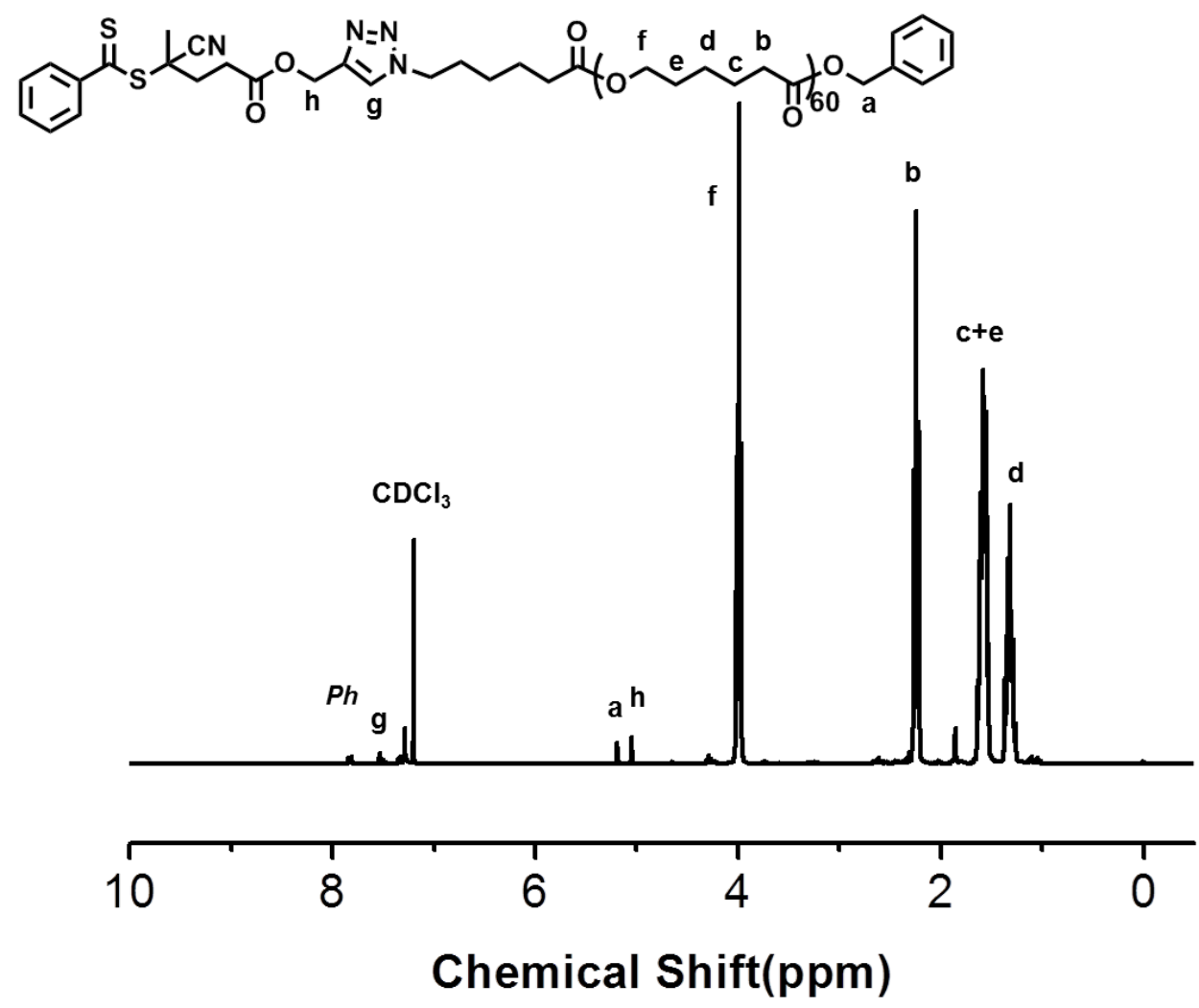

Figure S5. ${ }^{1} \mathrm{H}$ NMR spectrum of PCL Macro-CTA. 
Scheme S5. RAFT polymerization of CoAEMAPF 6 .<smiles>CC(CCCCCn1cc(COC(=O)CCC(C)(C)SC(=S)c2ccccc2)nn1)C(=O)OCCCCCC(=O)OCc1ccccc1</smiles><smiles></smiles>

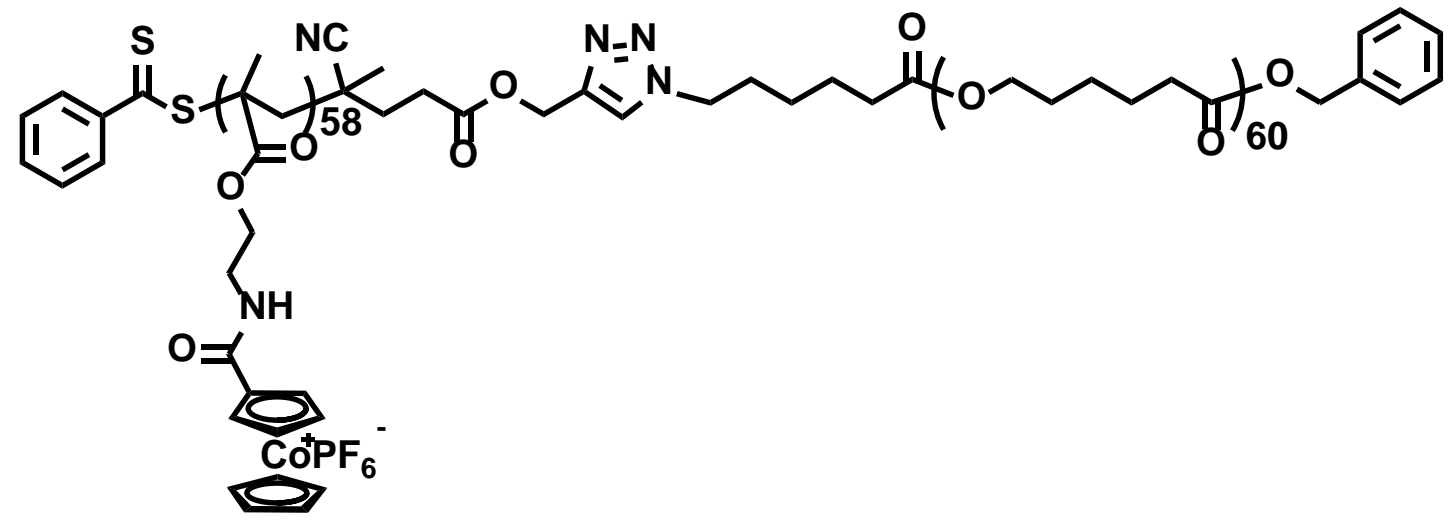

Synthesis of PCL-b-PCoAEMAPF 6 diblock copolymer. PCL-b-PCoAEMAPF 6 was synthesized through RAFT polymerization. PCL-RAFT macroinitiator (42 mg, $6 \mu \mathrm{mol}$ ), AIBN (0.3 mg, $1.8 \mu \mathrm{mol}$ ) and CoAEMAPF6 were dissolved by $0.3 \mathrm{~mL}$ dry DMF in a Schlenk flask. The reaction mixture was purged with $\mathrm{N}_{2}$ for $30 \mathrm{~min}$. The flask was placed into an oil bath preheated at $90^{\circ} \mathrm{C}$. The conversion was monitored by ${ }^{1} \mathrm{H}$ NMR. Polymerization was quenched when the conversion reached about $50 \%$. The polymers were precipitated in cold methanol to remove residual monomers. Yellow polymers were collected and dried in vacuum. Yield: $100 \mathrm{mg},{ }^{1} \mathrm{H}$ 
NMR (DMSO-d6, 300MHz, ppm): 6.25 (br, 58H, Cp ring), 5.9 -5.8 (br, 142H, Cp ring) 4.01 (t, $\left.120 \mathrm{H},-\mathrm{OCH}_{2} \mathrm{CH}_{2}-\right), 2.25$ (t, $\left.122 \mathrm{H},-\mathrm{OCO}-\mathrm{CH}_{2}-\right)$.

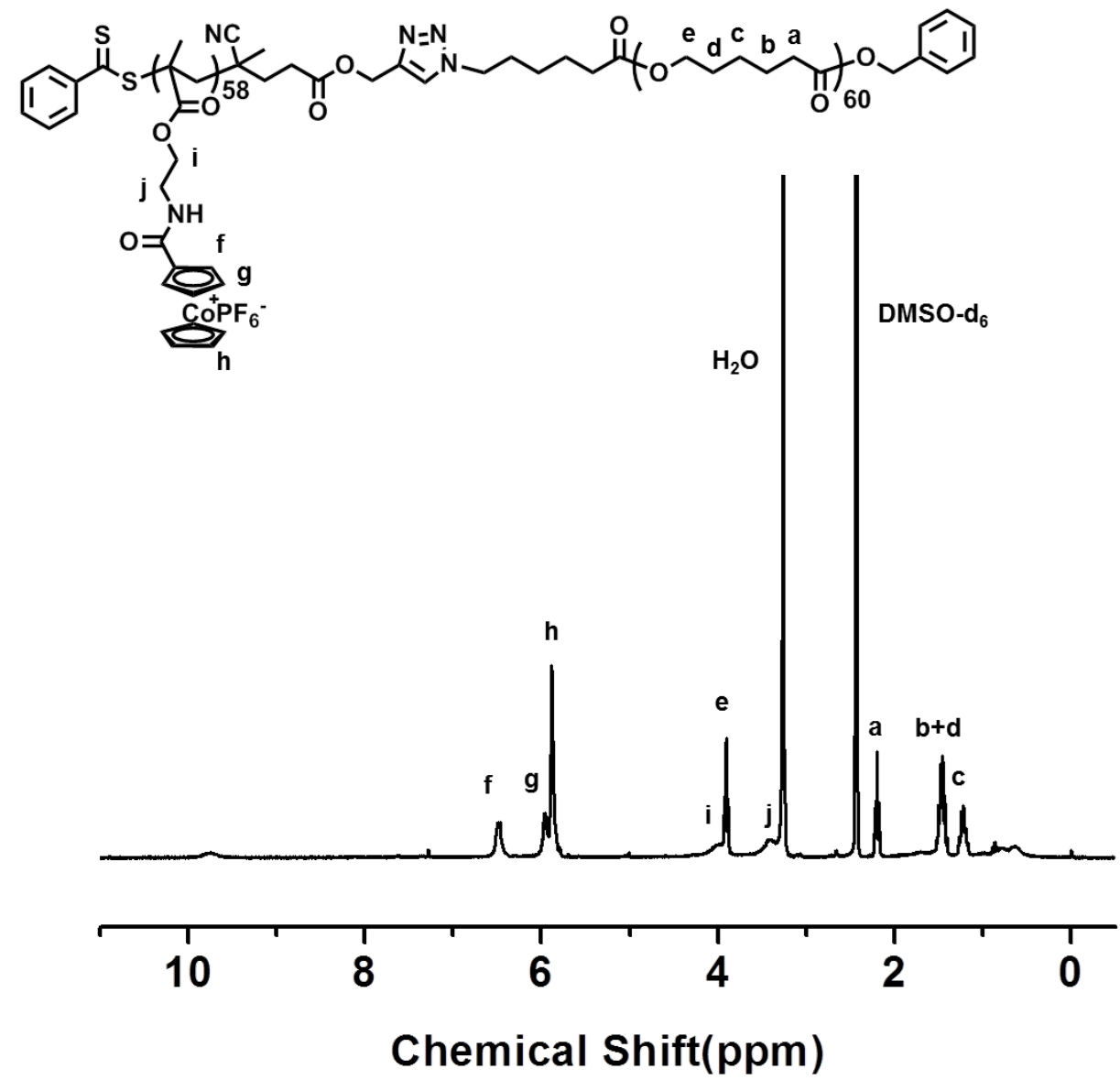

Figure S6. ${ }^{1} \mathrm{H}$ NMR spectrum of $\mathrm{PCL}_{61}-b$-PCoAEMA 58 .

Ion-exchange of PCL-b-PCoAEMAPF6 diblock copolymer. PCL- $b$-PCoAEMAPF 6 (100mg) was dissolved in $2 \mathrm{~mL}$ acetonitrile (CAN). Tetrabutylammonium chloride (TBACl) (2.0 g) was dissolved in $10 \mathrm{~mL}$ ACN. The polymer solution was added into TBACl solution. The ionexchanged polymers precipitated out. The polymers were collected and washed by ACN 3 times. The polymers were collected and dried in vacuum overnight. 


\section{Self-assembly of Cobaltocenium-Containing Block Copolymers}

PCL61- $b$-PCoAEMA $_{58}(2.0 \mathrm{mg})$ was dissolved in $4 \mathrm{~mL}$ distilled water and methanol respectively to make a concentration of $0.5 \mathrm{mg} / \mathrm{mL}$. The polymer solutions were annealed at $40{ }^{\circ} \mathrm{C}$ for 1 hour. After 1 hour, the solutions were cooled down to room temperature slowly. TEM samples were prepared by drop casting polymer solutions onto carbon coated copper grids and dried overnight.

\section{Transmission Electron Micrographs}
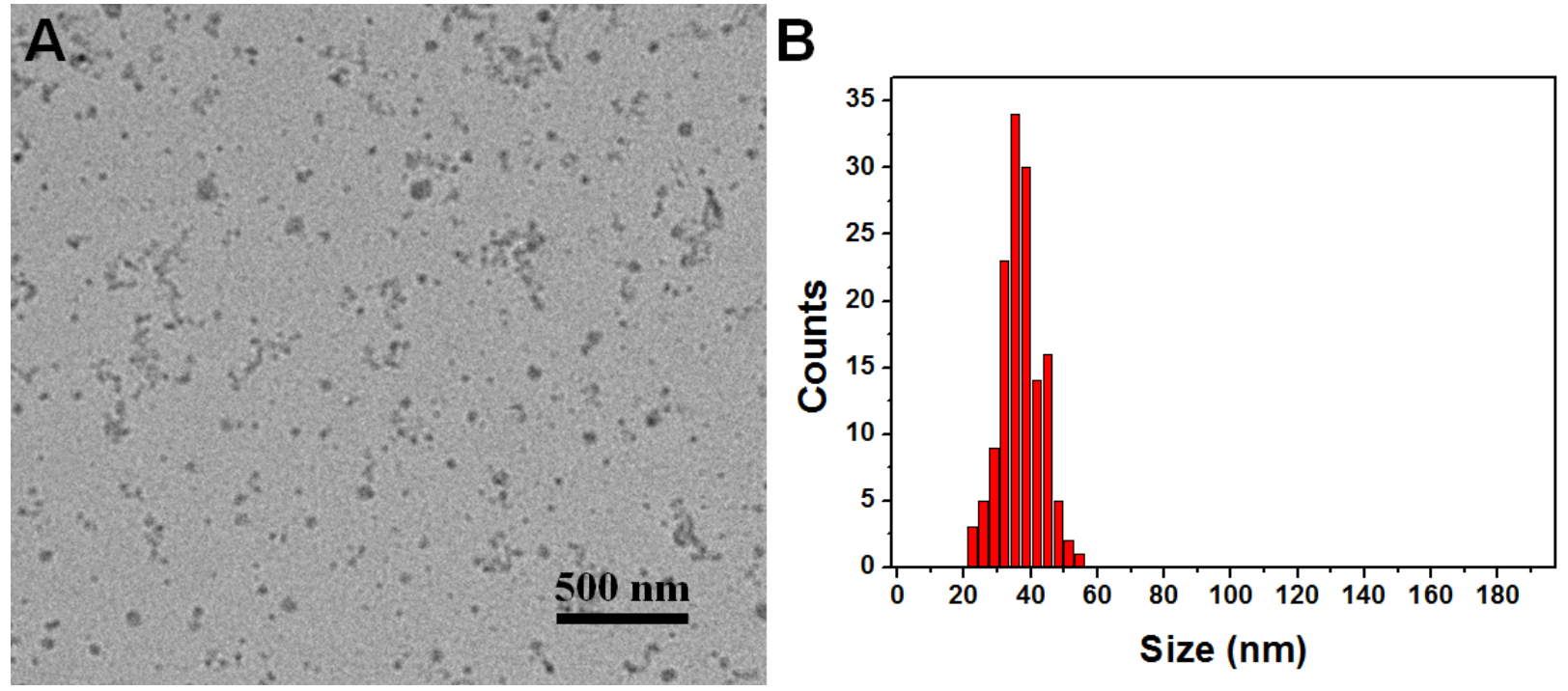

Figure S7. (A) TEM micrograph of sphere-shaped micelles of $\mathrm{PCL}_{61}-b$-PCoAEMA ${ }_{58}$ with a concentration of $0.5 \mathrm{mg} / \mathrm{mL}$ in water after annealing at $40{ }^{\circ} \mathrm{C}$ for 1 hour; and (B) size distribution of spherical micelles measured from TEM micrograph (A) analyzed by Image J (average diameter: $38 \mathrm{~nm})$. 

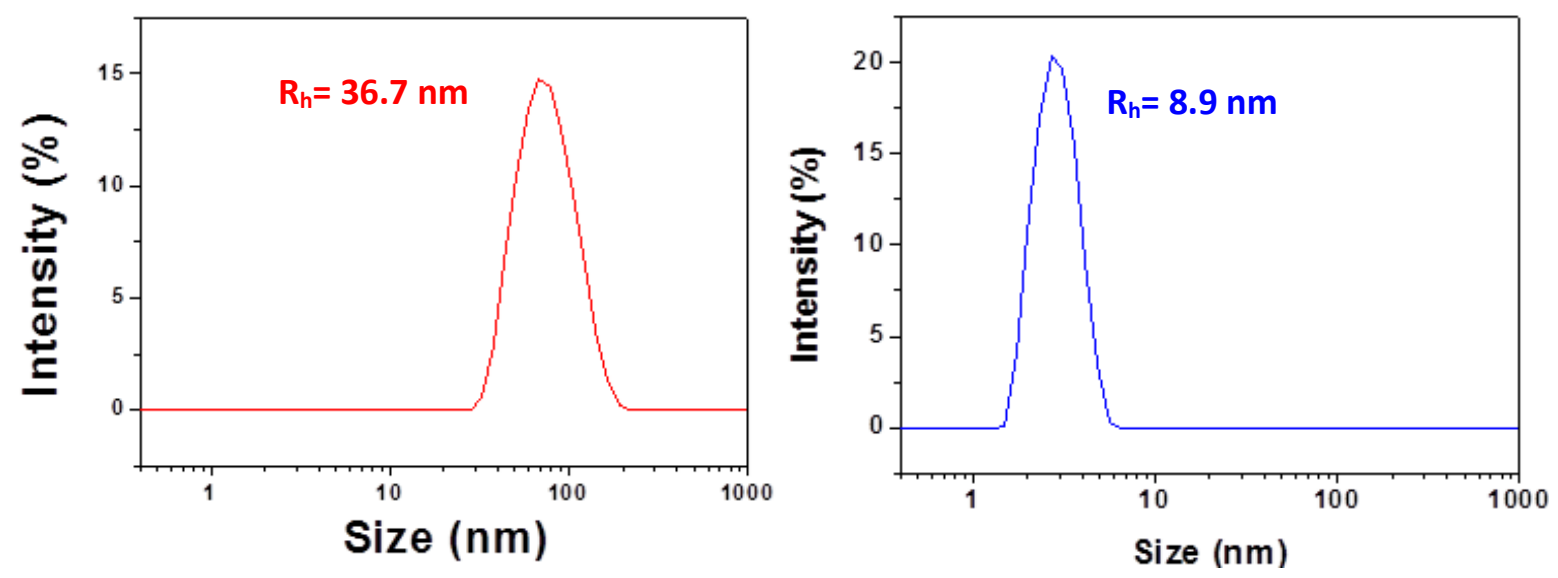

Figure S8. DLS profiles of spherical micelles from PCL61- $b$-PCoAEMA58: (Left) in water (red, corresponds to the TEM micrograph in Figure S7, $\mathrm{R}_{\mathrm{h}}=36.7 \mathrm{~nm}$ ); (Right) unimers dissolved in DMF (blue, $\mathrm{R}_{\mathrm{h}}=8.9 \mathrm{~nm}$ ) after annealing at $40{ }^{\circ} \mathrm{C}$.
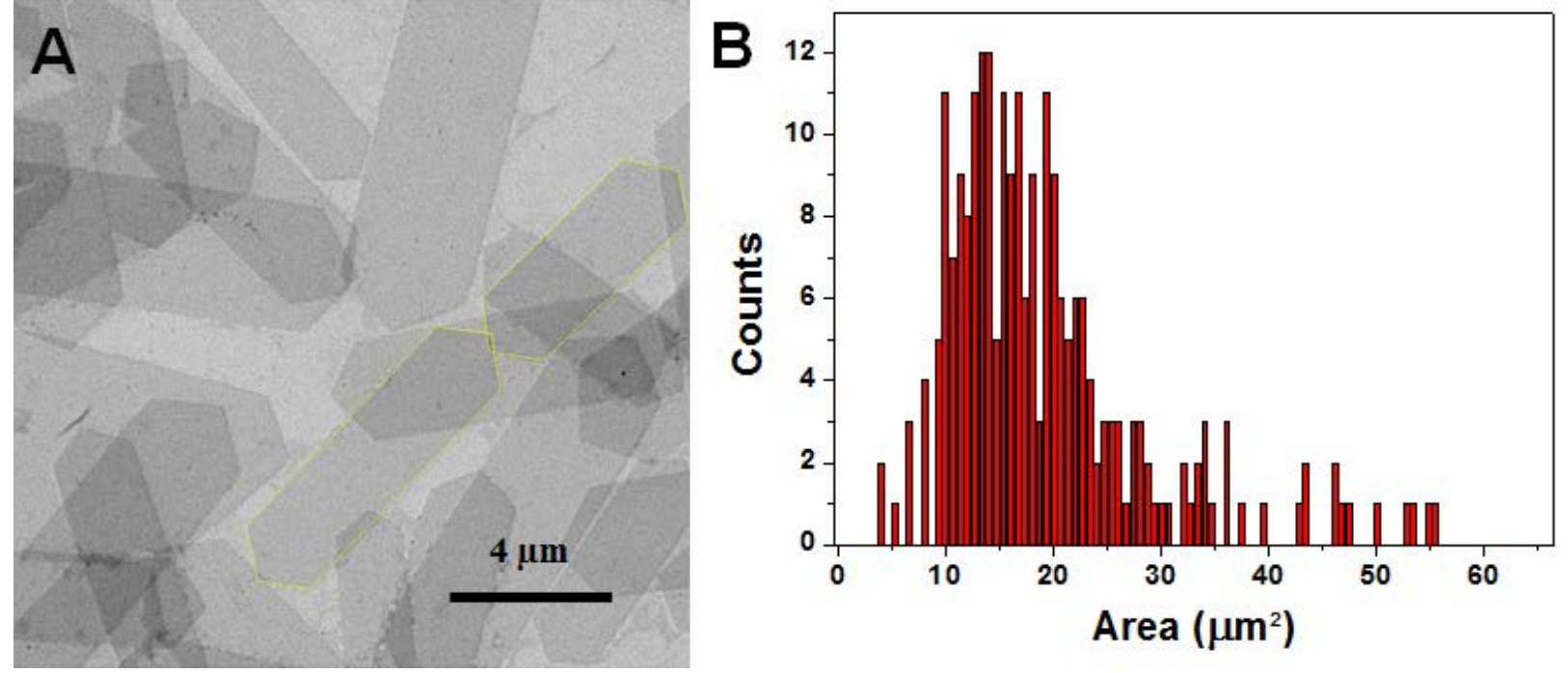

Figure S9. (A) Additional TEM micrograph of elongated hexagonal platelet of PCL61- $b$ PCoAEMA 58 with a concentration of $0.5 \mathrm{mg} / \mathrm{mL}$ in methanol and annealing at $40{ }^{\circ} \mathrm{C}$ for 1 hour, followed by cooling to $25{ }^{\circ} \mathrm{C}$ and then aging for 1 month; and (B) area distribution (average area $=19.6 \mu \mathrm{m}^{2}$, area dispersity $\left.=1.24\right)$. 


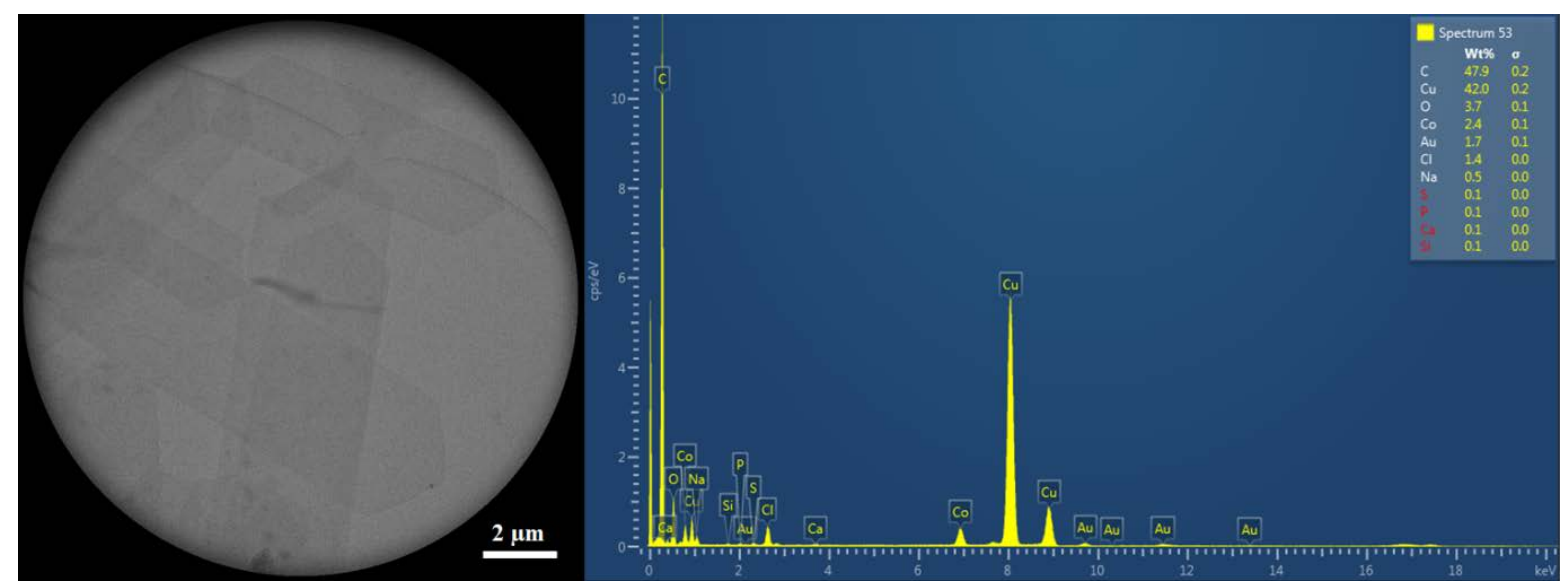

Figure S10. TEM-EDX analysis of hexagonal platelets.

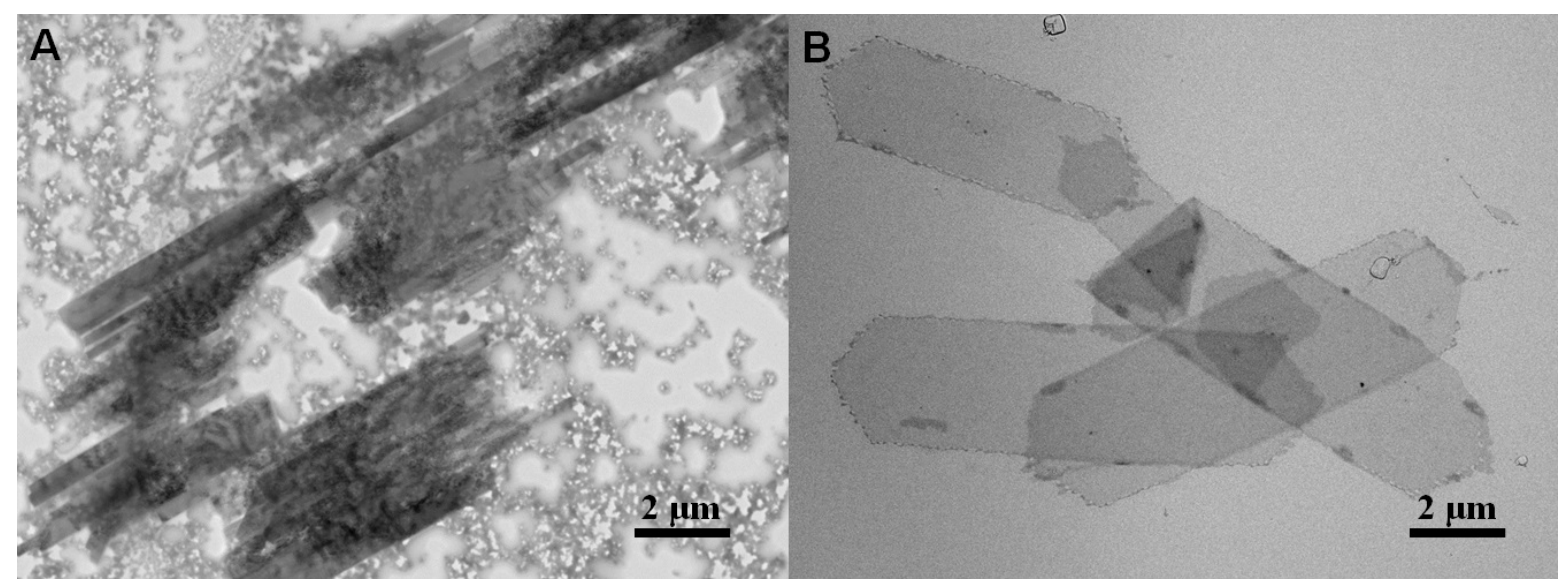

Figure S11. TEM micrographs of fragmented platelets after mixing PCL61-b-PCoAEMA58 in methanol with (A) water (v/v, 50/50); (B) $1.0 \mathrm{M} \mathrm{NaCl}$ aq. solution (v/v, 50/50). 

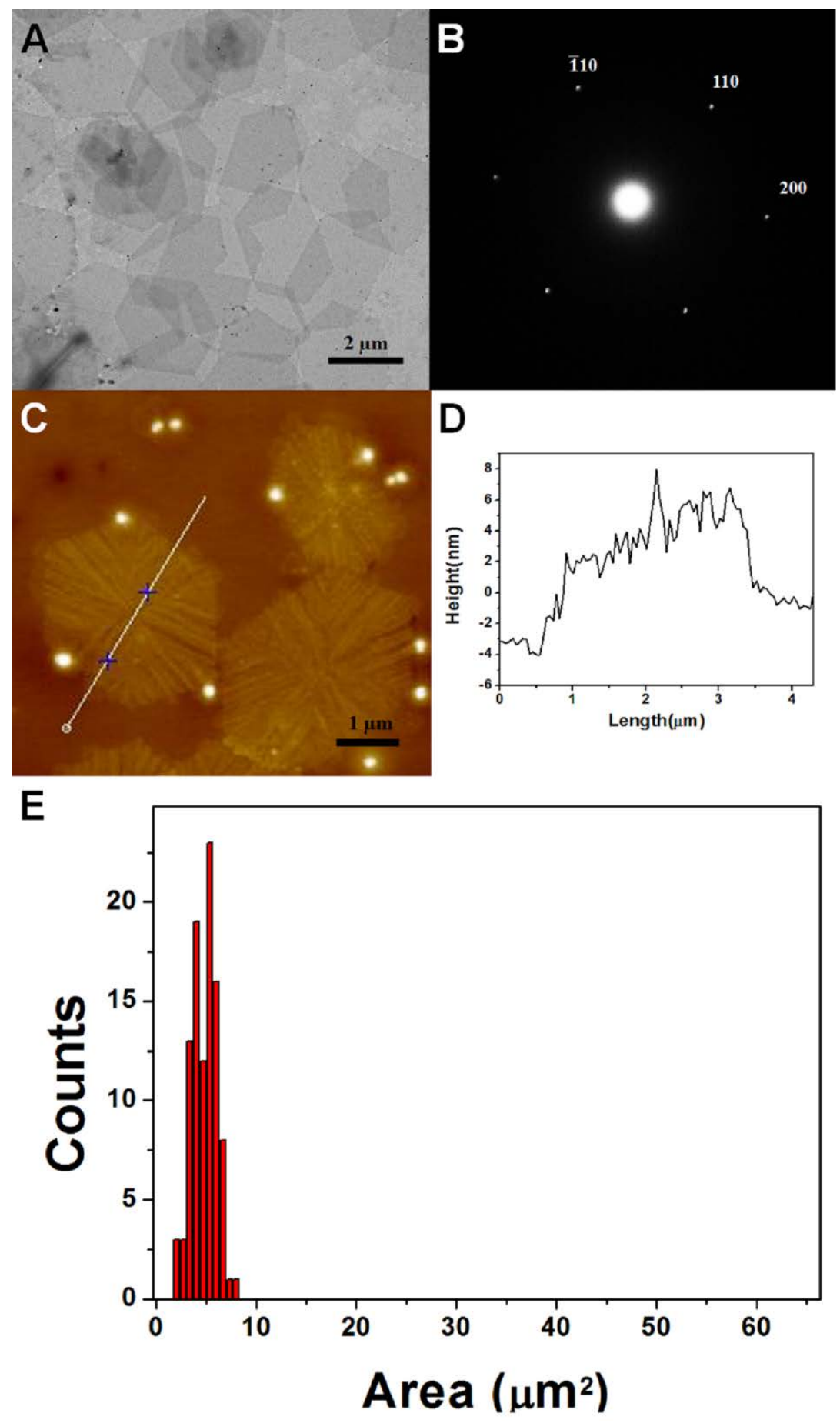

Figure S12. (A) TEM micrograph of wider hexagonal platelets obtained from PCL61-bPCoAEMA 244 in methanol $(0.5 \mathrm{mg} / \mathrm{mL})$ with heating at $40{ }^{\circ} \mathrm{C}$ for 1 hour, followed by cooling to $25^{\circ} \mathrm{C}$ and then aging for 1 month; (B) Electron diffraction; (C) AFM height image; (D) AFM height profile from image $\mathrm{C}$; and $(\mathrm{E})$ area distribution (average area $=2.76 \mu \mathrm{m}^{2}$, area dispersity $=$ 1.05). 

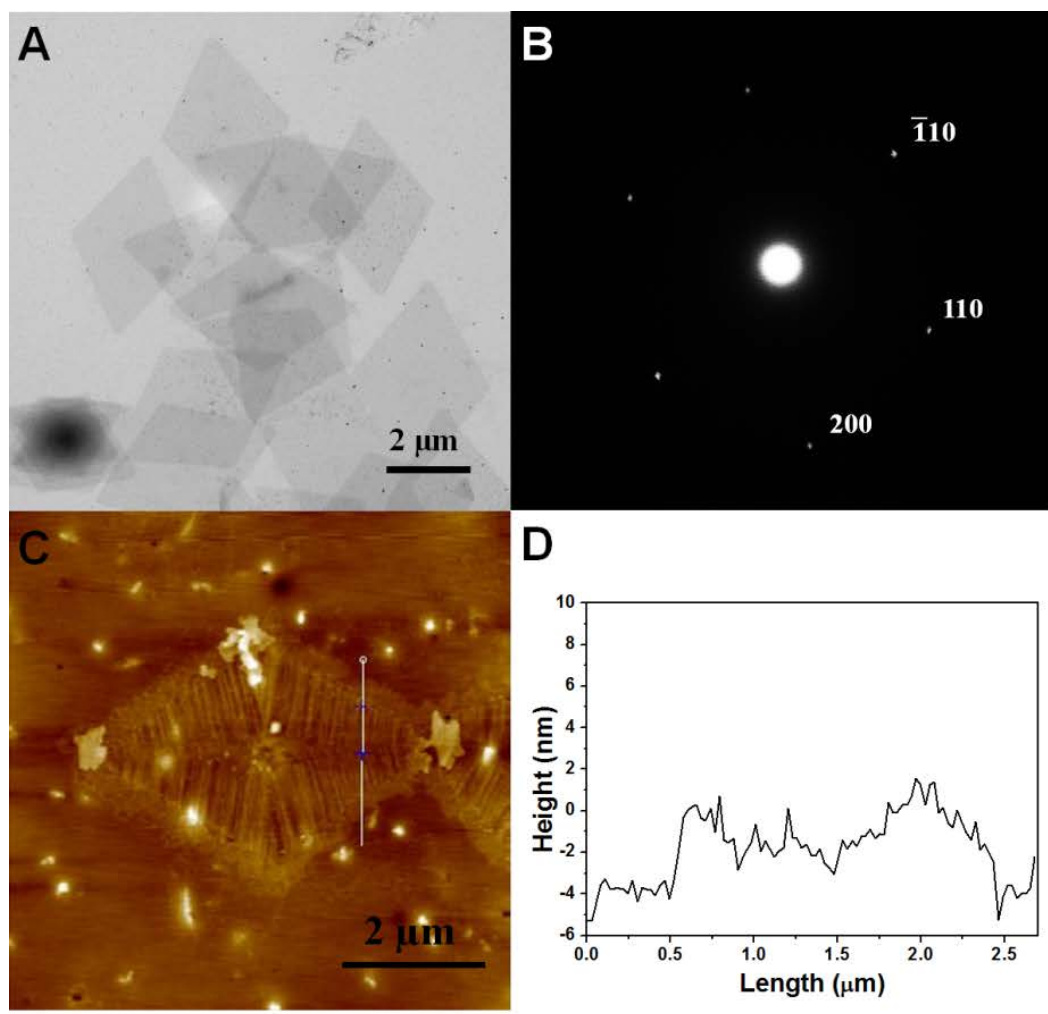

D

E

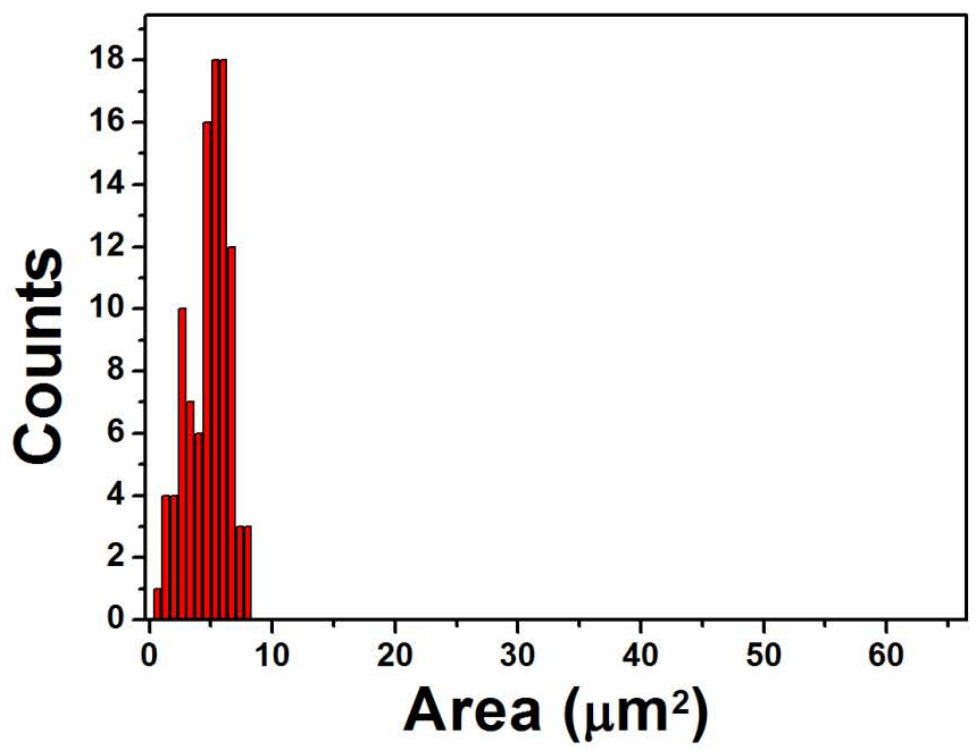

Figure S13. (A) TEM micrograph of diamond-shaped platelets of PCL61-b-PCoAEMA 344 in methanol $(0.5 \mathrm{mg} / \mathrm{mL})$ with heating at $40{ }^{\circ} \mathrm{C}$ for 1 hour, followed by cooling to $25{ }^{\circ} \mathrm{C}$ and then aging for 1 month; (B) Electron diffraction; (C) AFM height image; (D) AFM height profile from image $\mathrm{C}$; and $(\mathrm{E})$ area distribution (average area $=3.37 \mu \mathrm{m}^{2}$, area dispersity $=1.11$ ). 


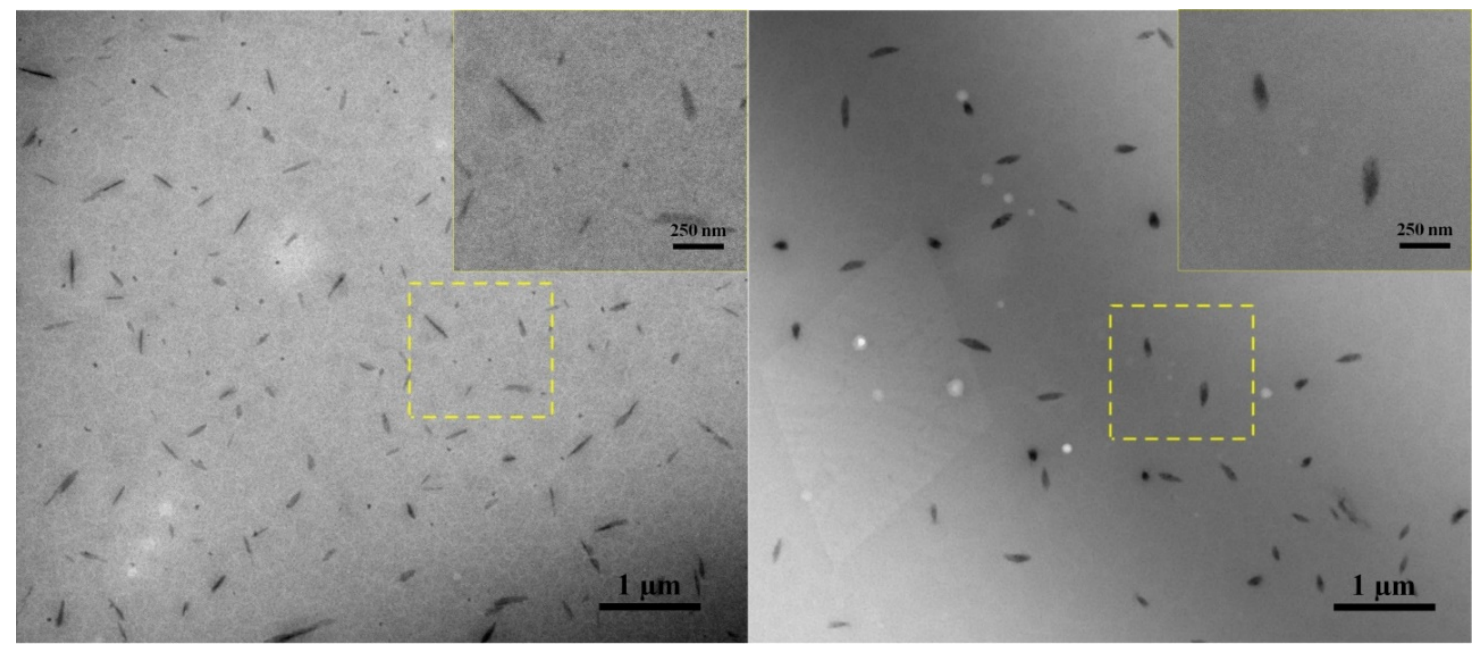

Figure S14. TEM micrographs of lenticular structures from PCL $61-b$-PCoAEMA 344 in methanol $(0.5 \mathrm{mg} / \mathrm{mL})$ obtained by annealing at $40{ }^{\circ} \mathrm{C}$ for 1 hour, followed by cooling to $25{ }^{\circ} \mathrm{C}$ and then aging for 1 month. Insert: magnified areas from dashed yellow squares.

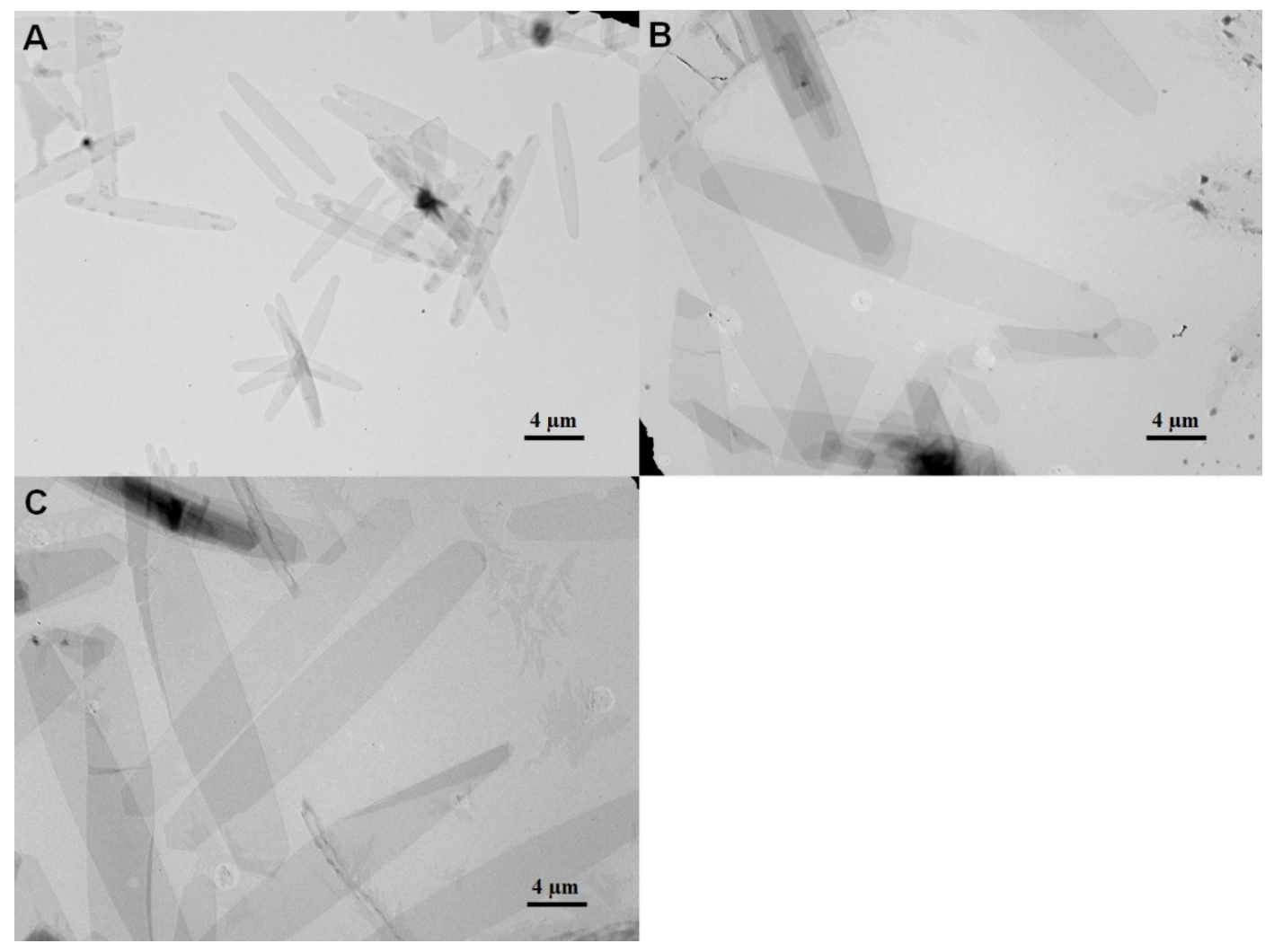

Figure S15. TEM micrographs of leaf-like platelets formed by blends of PCL $_{38}$ homopolymer in THF and (A) PCL $61-b$-PCoAEMA 58 ; (B) PCL $61-b$-PCoAEMA 244 ; and (C) PCL61- $b$-PCoAEMA 344 in methanol $(0.5 \mathrm{mg} / \mathrm{mL})$ (mass ratio of homopolymer to block copolymer $=1: 1)$. 


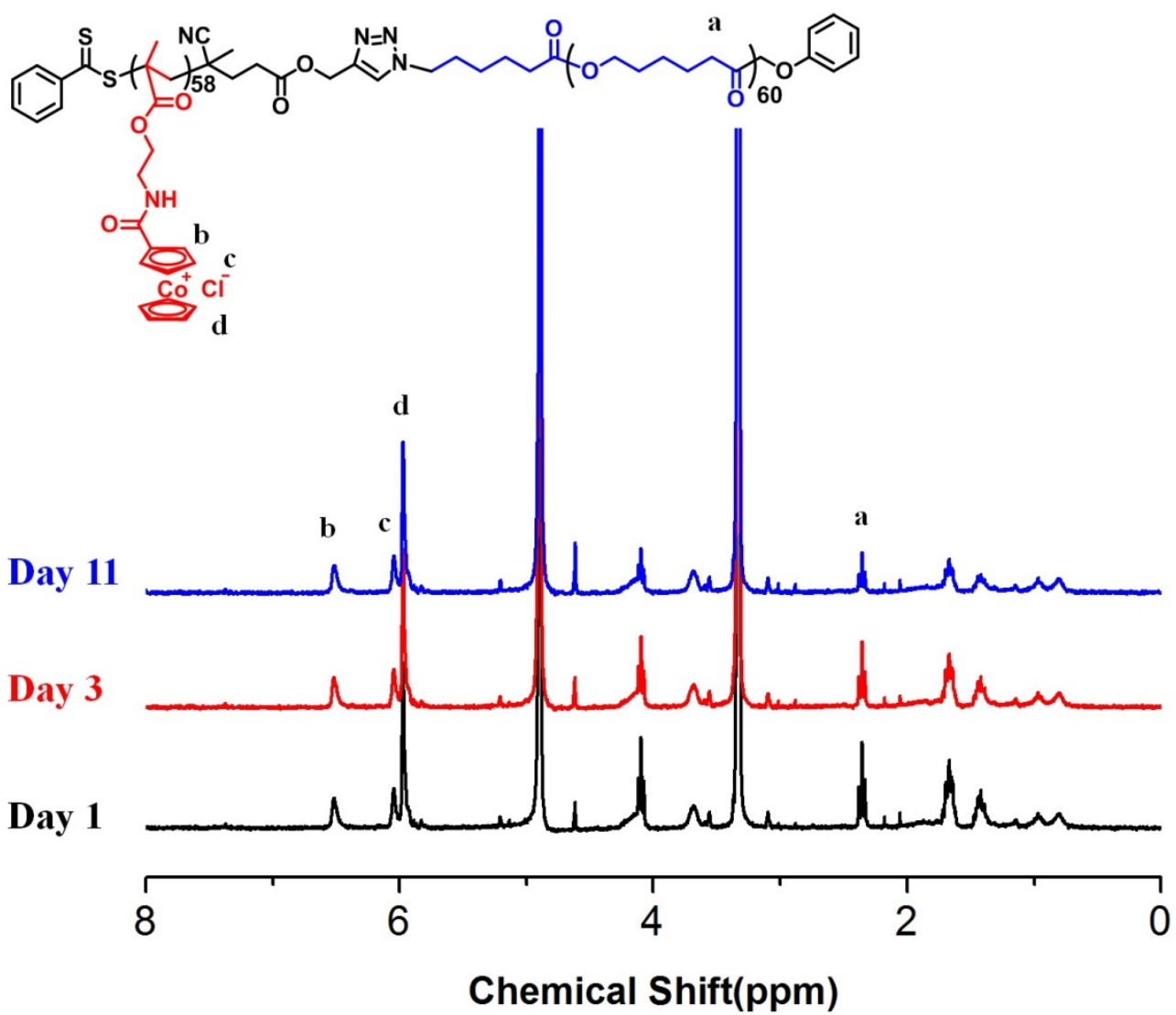

Figure S16. ${ }^{1} \mathrm{H}$ NMR spectra of PCL $61-b-P C o A E M A_{58}$ in methanol- $\mathrm{d}_{4}$.

\section{References:}

1. Zhang, J.; Yan, J.; Pageni, P.; Yan, Y.; Wirth, A.; Chen, Y. P.; Qiao, Y.; Wang, Q.; Decho, A. W.; Tang, C. Anion-Responsive Metallopolymer Hydrogels for Healthcare Applications. Sci. Rep. 2015, 5, 11914.

2. Moller, M.; Kange, R.; Hedrick, J. L. Sn(OTf) 2 and Sc(OTf) $)_{3}$ Efficient and versatile catalysts for the controlled polymerization of lactones. J. Polym. Sci. Polym. Chem. 2000, 38, 2067-2074. 